\title{
Semicontinuous emulsion copolymerization to obtain styrene- methyl acrylate copolymers with predetermined chemical composition distributions
}

\section{Citation for published version (APA):}

Schoonbrood, H. A. S., Thijssen, H. A., Brouns, H. M. G., Peters, M., \& German, A. L. (1993). Semicontinuous emulsion copolymerization to obtain styrene-methyl acrylate copolymers with predetermined chemical composition distributions. Journal of Applied Polymer Science, 49(11), 2029-2040.

https://doi.org/10.1002/app.1993.070491121

DOI:

10.1002/app.1993.070491121

Document status and date:

Published: 01/01/1993

\section{Document Version:}

Publisher's PDF, also known as Version of Record (includes final page, issue and volume numbers)

\section{Please check the document version of this publication:}

- A submitted manuscript is the version of the article upon submission and before peer-review. There can be important differences between the submitted version and the official published version of record. People interested in the research are advised to contact the author for the final version of the publication, or visit the DOI to the publisher's website.

- The final author version and the galley proof are versions of the publication after peer review.

- The final published version features the final layout of the paper including the volume, issue and page numbers.

Link to publication

\footnotetext{
General rights

- You may freely distribute the URL identifying the publication in the public portal. follow below link for the End User Agreement:

www.tue.nl/taverne

\section{Take down policy}

If you believe that this document breaches copyright please contact us at:

openaccess@tue.nl

providing details and we will investigate your claim.
}

Copyright and moral rights for the publications made accessible in the public portal are retained by the authors and/or other copyright owners and it is a condition of accessing publications that users recognise and abide by the legal requirements associated with these rights.

- Users may download and print one copy of any publication from the public portal for the purpose of private study or research.

- You may not further distribute the material or use it for any profit-making activity or commercial gain

If the publication is distributed under the terms of Article $25 \mathrm{fa}$ of the Dutch Copyright Act, indicated by the "Taverne" license above, please 


\title{
Semicontinuous Emulsion Copolymerization to Obtain Styrene-Methyl Acrylate Copolymers with Predetermined Chemical Composition Distributions
}

\author{
HAROLD A. S. SCHOONBROOD, HENK A. THIJSSEN, HARRY M. G. BROUNS, MATT PETERS, \\ and ANTON L. GERMAN* \\ Laboratory of Polymer Chemistry and Technology, University of Technology, PO Box 513, \\ $5600 \mathrm{MB}$ Eindhoven, The Netherlands
}

\begin{abstract}
SYNOPSIS
Four types of emulsion copolymerization processes were applied to produce various styrenemethyl acrylate copolymer latices. (1) Batch emulsion copolymerization. (2) Monomer starved semicontinuous emulsion copolymerization, i.e., a monomer mixture of constant composition was fed to the reactor at a constant rate. Sufficiently low addition rates led to homogeneous copolymers. (3) Optimal addition rate profiles were used to produce homogeneous emulsion copolymers in relatively short times. The profiles were determined in a semiempirical way, and applied to three different copolymer compositions. (4) We made an attempt to determine an addition rate profile to produce a heterogeneous emulsion copolymer with predetermined heterogeneity, i.e., a copolymer of which the chemical composition distribution (CCD) did not consist of one narrow peak, as with homogeneous copolymers, but had a predetermined broadness profile. Strategies (2) and (3) were used to produce homogeneous emulsion copolymers with varying fractions of styrene. Strategy (3) was also used to demonstrate the influence of the monomer ratio on the kinetics. The advantage of this method is that the monomer ratio is constant over the whole conversion range in the latex particles. High performance liquid chromatography (HPLC) was used to determine the homogeneity/heterogeneity of the copolymers produced, and proved to be invaluable in determining the optimal addition rate profile. The final goal will be to study the influence of the chemical composition distribution (CCD) on mechanical properties of these copolymers, as both homopolymers used in this study have quite differentglass transition temperatures; the results will be published later. (C) $1993 \mathrm{John}$ Wiley \& Sons, Inc.
\end{abstract}

\section{INTRODUCTION}

Since there is an increasing demand for special polymers, more and more copolymers and even terpolymers are being used in industry. The problem one can run into is that when these copolymers are made batchwise, composition drift generally influences the chemical composition distribution. Due to the monomer partitioning, this problem can be even worse when the copolymers are made in emulsion,

\footnotetext{
* To whom correspondence should be addressed.
}

Journal of Applied Polymer Science, Vol. 49, 2029-2040 (1993) (c) 1993 John Wiley \& Sons, Inc. in those cases where the more reactive monomer is also the less water-soluble monomer. ${ }^{1}$

In order to produce a copolymer latex with desired properties, one needs to know how to control the chemical composition distribution of the copolymers. This has previously been realized by many researchers, by producing emulsion copolymers semicontinuously, which involves adding the monomers to the reaction mixture during the course of the reaction. ${ }^{2-5}$ The easiest way to achieve is to add the monomer mixture (pure or pre-emulsified) at a constant, low rate (starved conditions). Many investigators have applied this strategy. ${ }^{2-10}$ However, working under starved conditions means that the monomer concentrations are low, and this leads to 
low polymerization rates and long reaction times. Therefore, Arzamendi and Asua ${ }^{11,12}$ proposed a method to make homogeneous copolymers in emulsion at high monomer concentrations, by adding the more reactive monomer (via an optimal addition rate profile) to the reaction mixture containing all of the less reactive monomer [vinyl acetate (VAc); they copolymerized VAc with methyl acrylate (MA)]. By using this method they could keep the ratio of the monomers inside the latex particles constant. Since the method of the optimal addition rate profile leads to short reaction times, heat removal can be a limiting factor. Therefore, they also looked at the situation where the reactor had limited capacity for heat removal, adding the less reactive monomer to the reactor at a constant rate, and adding the second monomer via an optimal addition rate profile..$^{13}$ In our laboratory, ${ }^{14}$ this technique was applied to the emulsion copolymerization of styrene (S) and methyl acrylate (MA), but a somewhat different procedure was utilized to calculate the optimal addition rate profile. Arzamendi et al. ${ }^{15}$ applied this technique to the emulsion copolymerization of methyl methacrylate and ethyl acrylate ( two different compositions ) and Urquiola et al. ${ }^{16}$ also to VAcMA copolymerization. Very recently, Arzamendi et al. ${ }^{17}$ published results of simulations of reactions with optimal addition rate profiles for homogeneous terpolymers of styrene, methyl methacrylate, and ethyl acrylate. A more elaborate approach to modeling semicontinuous (emulsion) polymerizations was published by Hamielec et al. ${ }^{18,19}$ They modeled polymerizations, including molecular weight distributions, with empirically measured kinetic parameters. They were able to model batch, semicontinuous, and continuous polymerizations, even taking into account heat removal. However, if few of the kinetic parameters are known or can be estimated, the approach presented by Asua et al. ${ }^{11,12}$ is more appropriate, depending on what one wants to look at.

In the present investigation we have applied a procedure very similar to that developed by us previously ${ }^{14}$ to produce homogeneous S-MA copolymer latices with varying amounts of styrene. A similar procedure was followed to produce a copolymer with an average composition of $25 \% \mathrm{~S}$, but with a predetermined broad CCD. In all cases we added $\pm 1 \%$ chain transfer agent (CTA) to minimize the influence of addition strategy on the molecular weight distribution, since this has a significant influence on mechanical properties, which might obscure the influence of the CCD, which is what we want to study eventually. The use of CTA might also prevent gel formation during the starved con- ditions process. Note that the goal is to produce several different CCDs, and therefore we did not consider other aspects like the effect of high polymerization rates on heat removal from the reactor, etc. We compared batch and semicontinuous reactions with respect to composition drift, i.e., how the factors that govern composition drift in batch reactions also control the homogeneity of the semicontinuously formed copolymers. We also studied the kinetics of the reactions with optimal addition rate profiles.

\section{EXPERIMENTAL}

Applied chemicals are: styrene (S), methyl acrylate (MA), sodium persulfate (SPS, initiator), $n$-dodecyl mercaptan (NDM, chain transfer agent), sodium bicarbonate (SB, buffer) (all p.a., Merck), sodium dodecyl sulfate (SDS, emulsifier, Fluka, 99\%). All experiments were carried out in a 1.3-L stainlesssteel reactor. Temperature was always kept at 323 $\mathrm{K}$. The reactor configuration has been described elsewhere. ${ }^{1}$ During semicontinuous reactions the monomer feed (never emulsified) was added with a Dosimat 665 (Metrohm), and the feed was computer-controlled (Atari 1040 ST).

Conversion was followed by solid content analysis. Copolymer composition was sometimes checked with ${ }^{1} \mathrm{H}$-NMR. The spectra were recorded with a Bruker AM 400 spectrometer $(400 \mathrm{MHz})$ at $298 \mathrm{~K}$ using $\mathrm{CDCl}_{3}$ as a solvent. High performance liquid chromatography (HPLC) was used to determine the chemical composition distribution (CCD) of the styrene-methyl acrylate copolymers. Gradient elution was applied to obtain the CCDs. The procedure has been described elsewhere. ${ }^{20}$ The column was a silica column [Zorbax Sil (Rockland) Silica column with Zorbax Sil precolumn $4.6 \mathrm{~mm}$ ID $* 15 \mathrm{~cm}$ ]. The column was used at room temperature. We applied an eluent consisting of $n$-heptane and THF: $n$ Heptane is a nonsolvent for all copolymers. The gradient was linear, and the composition shifted from $80 \% n$-heptane $/ 20 \%$ THF to $60 \% n$-heptane / $40 \%$ THF after $1 \mathrm{~min}$ and $100 \%$ THF after $16 \mathrm{~min}$. Flow rate was $0.6 \mathrm{~mL} / \mathrm{min}$. We used a flame ionization detector with a moving wire (FID).$^{21} \mathrm{UV}$ detection of polyacrylates is not feasible due to the low absorption of polyacrylates. However, FID responses of poly (methyl acrylate) and polystyrene are comparable. Molecular weights were determined with gel permeation chromatography (GPC). The chromatographic system (Waters Associates) was equipped with a differential refractometer and a 2 Shodex linear column, kept at $40^{\circ} \mathrm{C}$. The eluent was 
$\mathrm{THF}$, and the elution rate was $1 \mathrm{~mL} / \mathrm{min}$. The samples for ${ }^{1} \mathrm{H}-\mathrm{NMR}$ and HPLC and GPC were taken from samples used for solid content analysis. The particle sizes, needed to calculate the number of particles, were determined with dynamic light scattering (DLS). We could not check the diameters with transmission electron microscopy.

\section{RESULTS AND DISCUSSION}

During the semicontinuous reactions, the total amounts of monomers added was such that all latices had a final solids content of about $17 \%$, corresponding to an initial monomer to water ratio $(\mathrm{M} / \mathrm{W})$ of $0.2 \mathrm{~g} / \mathrm{g}$ for batch reactions. All reactions were carried out at $50^{\circ} \mathrm{C}$, and the stirring rate was $250 \mathrm{rpm}$. NDM was, as stated before, added in all cases in order to (i) limit the molecular weights and (ii) diminish the effect of addition strategy on the molecular weight distribution (MMD); it is known from the literature ${ }^{22}$ that there can be an effect. Addition of NDM could decrease the extent of this by exhibiting a much larger effect on MMD than the addition strategy. To check this, we measured the MMDs of the final products. The batch reactions and reactions under starved conditions were performed ab initio (without seed); the reactions with (optimal) addition rate profiles were started from a seed latex. This was done to avoid irreproducibility due to the nucleation stage. By doing so, the number of particles could be controlled and also the reaction rate, which is very important in reactions where both monomers are fed to the reactor at different rates. The seed always had the same average composition as the desired copolymer. The size of the seed particles was small enough to ensure that the polymer in the seed particles had a negligible contribution to the final CCD compared with the contribution of the copolymer that was polymerized onto them. We

Table I Recipe of the Batch Reactions

\begin{tabular}{ll}
\hline & $(\mathrm{g})$ \\
\hline & \\
$\mathrm{H}_{2} \mathrm{O}$ & 900 \\
$\mathrm{SDS}$ & 3.0 \\
$\mathrm{SPS}$ & 0.264 \\
$\mathrm{SB}$ & 0.1 \\
$\mathrm{MA}+\mathrm{S}$ & $180^{\mathrm{a}}$ \\
$\mathrm{NDM}$ & 1.8 \\
\hline
\end{tabular}

\footnotetext{
a The separate amounts of MA and $S$ depend on the desired molar composition.
}

Table II Recipes of Semicontinuous Reactions with Constant Addition Rates

\begin{tabular}{lcc}
\hline & $\begin{array}{c}\text { Initial Charge } \\
(\mathrm{g})\end{array}$ & $\begin{array}{c}\text { Continuous Addition } \\
(\mathrm{g})\end{array}$ \\
\hline $\mathrm{H}_{2} \mathrm{O}$ & 900 & - \\
$\mathrm{SDS}$ & 3.0 & - \\
$\mathrm{SPS}$ & 0.264 & - \\
$\mathrm{SB}$ & 0.1 & - \\
$\mathrm{MA}+\mathrm{S}$ & - & $180^{\mathrm{a}}$ \\
$\mathrm{NDM}$ & - & 1.8 \\
\hline
\end{tabular}

${ }^{\mathrm{a}}$ The separate amounts of MA and $\mathrm{S}$ depend on the desired molar composition.

found that neither DLS nor transmission electron microscopy could give reliable diameters of the seed particles. However, the exact size of the seed particles is not important. The seed latices were prepared by semicontinuous addition of a monomer mixture with the same composition as the desired composition of the copolymer in the seed latex. These reactions were carried out at $80^{\circ} \mathrm{C}$. The amount of seed latex in the recipes was such that the particle number was about $5 \times 10^{17} \mathrm{~L}^{-1}$ (the calculation was based on the diameter that was obtained from DLS). The particle diameters of the final latices could be measured more reliably.

Batch reactions and reactions under starved conditions were carried out according to the recipes of Tables I and II. In the experiments with (optimal) addition rate profiles, the reactor was always precharged with all ingredients [including seed and all of the methyl acrylate (MA) and part of the styrene (S) ], and the remaining part of the $S$ was added during the reaction. The recipes for these reactions are shown in Table III. The total volume decrease of the reaction volume due to sampling for analyses of solid content and particle diameter was always less than $5 \%$ in semicontinuous reactions. Corrections were made to account for this decrease.

\section{Batch Reactions}

In order to put the results of the semicontinuous reactions into perspective, we did three batch reactions with $\mathrm{M} / \mathrm{W}=0.2$, but with varying overall molar compositions, namely $F_{\mathrm{S}}$ (overall fraction of $\mathrm{S}$ in copolymer $)=0.25,0.50$, and 0.80 . Figure 1 shows the CCDs of these reactions as determined with HPLC/FID. The CCD of the copolymer with $25 \mathrm{~mol} \%$ is significantly different from that measured previously ${ }^{14}$ with UV detection. In that case, 
Table III Recipes for the Reactions with the Addition Rate Profiles

\begin{tabular}{lllll}
\hline & & $F_{S}=0.25$ & $F_{S}=0.50$ & $F_{S}=0.80$ \\
\hline $\mathrm{H}_{2} \mathrm{O}$ & Initial charge (g) & & & \\
$\mathrm{SDS}$ & Initial charge (g) & $900^{\mathrm{a}}$ & $900^{\mathrm{a}}$ & $900^{\mathrm{a}}$ \\
$\mathrm{SPS}$ & Initial charge (g) & $1.00^{\mathrm{a}}$ & $1.00^{\mathrm{a}}$ & $1.00^{\mathrm{a}}$ \\
$\mathrm{SB}$ & Initial charge (g) & 0.264 & 0.264 & 0.264 \\
$\mathrm{Seed} \mathrm{latex}$ & Initial charge (g) & 0.100 & 0.100 & 0.100 \\
$\mathrm{MA}$ & Initial charge (g) & 27.939 & 20.492 & 12.658 \\
$\mathrm{~S}$ & Initial charge (g) & 126.323 & 80.626 & 30.635 \\
$\mathrm{~S}$ & Semicontinuous addition (g) & 8.715 & 30.976 & 115.969 \\
$\mathrm{NDM}$ & Initial charge (g) & 42.22 & 66.53 & 32.273 \\
$\mathrm{NDM}$ & Semicontinuous addition (g) & 1.35 & 1.116 & 1.466 \\
\hline
\end{tabular}

a The amount of SDS in the seed was subtracted from $1.00 \mathrm{~g}$ so that the total amount of SDS always was $1.00 \mathrm{~g}$.

it was impossible to detect the poly (methyl acrylate) peak with HPLC. We were now able to show unambiguously that there is indeed a homopolymer peak in the CCD as a result of composition drift. Concerning the CCD of the copolymer with $50 \%$ of $S$, we have to point out that the average fraction of $\mathrm{S}$ in the copolymer as calculated from this CCD is higher than $50 \%$. The reason for this is probably that polymer is formed with fractions of $\mathrm{S}$ much lower than $50 \%$ due to composition drift, but this polymer is not detected because of its low concentration. In fact, calculating the average composition from a broad CCD is only possible if the measurement is very accurate. The exact position of the baseline is important in this case, because a small shift of the baseline can result in a relatively large change in apparent concentration of polymer, which has a low concentration. ${ }^{1} \mathrm{H}$-NMR showed that the average composition was $50 \%$.

It can be clearly seen that the broadness of the CCD depends strongly on the overall composition. The lower $F_{\mathrm{S}}$, the broader the CCD, which means that composition drift is strongest in the case of the lowest $F_{\mathrm{S}}$, even leading to a bimodal distribution. This can be explained qualitatively using the monomer partitioning data and reactivity ratios. The monomer partitioning behavior of this system is such that the composition drift due to the difference between the monomer ratio in the particles and the overall monomer ratio is not strongly dependent on the overall fraction of $\mathrm{S}$. Mass balance calculations with monomer partitioning data as determined by van Doremaele et al. ${ }^{14}$ show this. The strong composition drift with low fractions of $\mathrm{S}$ must therefore primarily result from the copolymerization kinetics as described by the reactivity ratios $\left(r_{\mathrm{S}}=0.73\right.$ and $r_{\text {MA }}=0.19^{1}$ at $323 \mathrm{~K}$ ). As can be seen in Figure 2, where we plotted the instantaneous fraction of $S$ in the copolymer $\left(F_{\mathrm{S}}\right)$ versus the fraction of $\mathrm{S}$ in the feed $\left(f_{\mathrm{S}}\right)$, the lower $f_{\mathrm{S}}$, the higher the relative difference between $F_{\mathrm{S}}$ and $f_{\mathrm{S}}$ and the stronger the composition drift. Judging from the above results, we expect the copolymers with $80 \mathrm{~mol} \% \mathrm{~S}$ to be quite homogeneous in all process modes.

\section{Reactions under Starved Conditions}

We did reactions under starved conditions with two different fractions of S ( 50 and $80 \mathrm{~mol} \%$ ), and each reaction was carried out using three different addition times $(4,8$, and $32 \mathrm{~h}$, in all cases adding 120 $\mathrm{g}$ of monomer mixture to $600 \mathrm{~g}$ of water). These reactions are very simple because of the constant addition rates. The reactions were performed for comparison with the results of reactions with optimal addition rate profiles, which are less simply carried out. We have done similar reactions previously with $25 \mathrm{~mol} \% \mathrm{~S}^{14}{ }^{4}$ Figures $3 \mathrm{a}$ and $3 \mathrm{~b}$ show the overall conversions $\left(X_{0}\right)$ of these reactions versus fractional time $t / t_{0}, t_{0}$ being the total addition time. Our results are comparable to those found earlier, ${ }^{14}$ i.e., the longer the addition times, the higher the instantaneous conversions of monomer to polymer.

Adding the monomer mixture at low rates leads to a situation where the addition rate determines the reaction rate. In this way, one can effectively influence the concentrations of the monomers inside the latex particles, where polymerization takes place throughout the greater part of the reaction. Early on in the reaction, the system reaches a steady state in which the polymerization rate equals the addition rate for both monomers. This must mean that the ratio of the monomers in the particles corresponds to the value that can be calculated from the reactivity ratios and copolymer composition. It is obvious that it takes some time before this situation is 

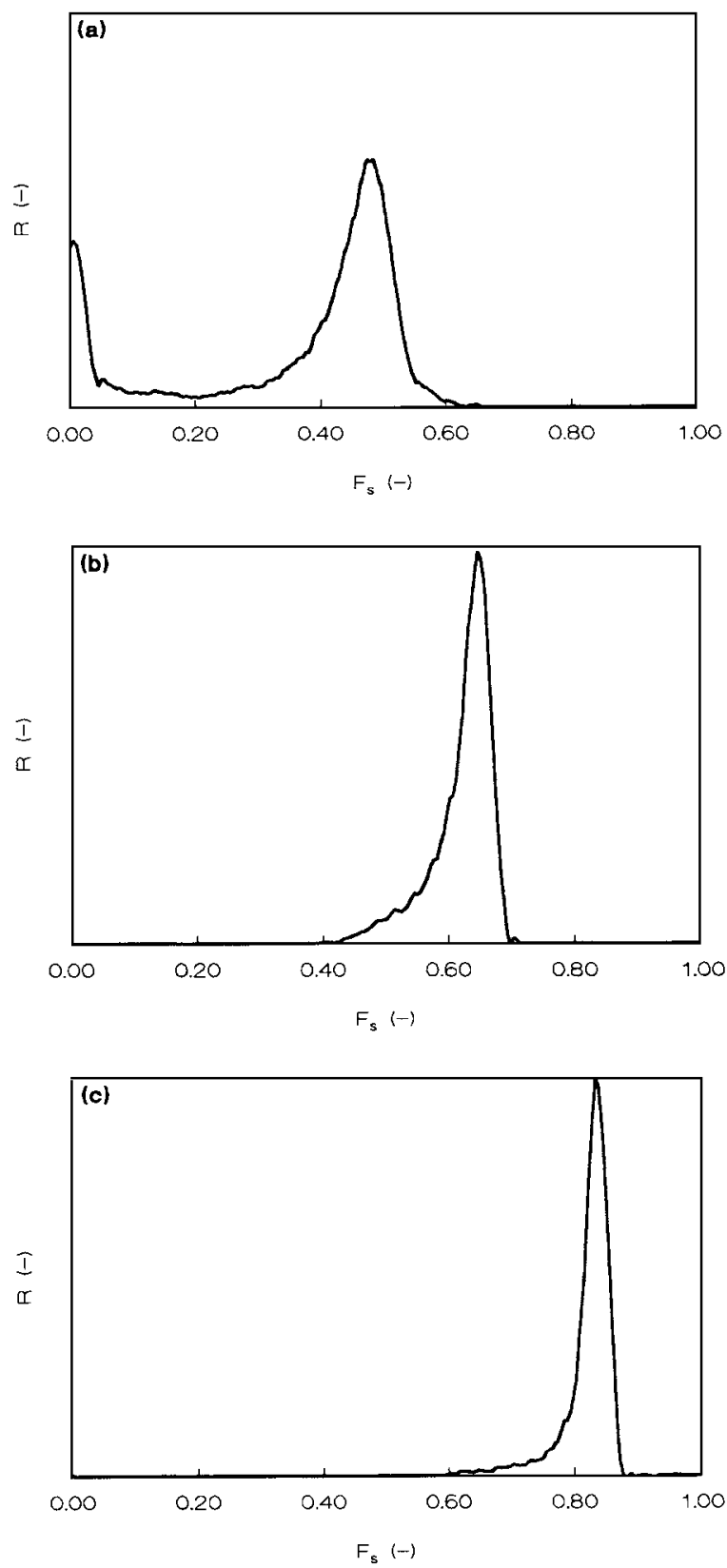

Figure 1 Experimentally determined CCDs of the batch reactions with $F_{\mathrm{S}}=0.25,0.50$, and $0.80 . R$ designates the relative abundance and is in arbitrary units.

reached, and it is during this time that composition drift occurs. There is a relatively large difference between reaction rate and addition rate in the beginning of the reaction as can be seen in Figures $3 a$ and $3 \mathrm{~b}$. Later during the reaction, the curve of conversion versus time is parallel to the line, indicating $100 \%$ instantaneous conversion showing that the reaction rate equals the addition rate. One can also assume that particle nucleation takes place over a period of time and that the number of particles is not fixed in the beginning. If the number of particles increases with time, then it is evident that in the beginning polymerization rate is lower than the addition rate which leads to composition drift. The composition drift is clearly shown in Figures 4a and $4 \mathrm{~b}$. Here we plotted the cumulative fractions of $S$ in the copolymer as determined with ${ }^{1} \mathrm{H}-\mathrm{NMR}$ versus fractional time. In all cases we see that the conversion of $\mathrm{S}$ in the beginning is larger than the conversion of MA, leading to S-rich copolymers, except for the very beginning, where the absence of a significant number of particles could cause monomer consumption processes other than those normally occurring in polymer particles to prevail. In the literature, ${ }^{1,14}$ aqueous phase polymerization has often been assumed to explain the relatively high consumption rate of MA. However, poly (methyl acrylate) (PMA) is not water-soluble, so that it is hard to see that aqueous phase polymerization could occur to a large enough extent. Note that in these figures $t / t_{0}$ ranges from 0 to 0.5 and $F_{\mathrm{S}}$ from 0.4 to 1 .

Figures $5 \mathrm{a}$ and $5 \mathrm{~b}$ show the CCDs of the reactions under starved conditions. In Figure 5a we see that the average composition of the copolymer formed in the 4-h addition, as calculated from the $\mathrm{CCD}$, is about $60 \% \mathrm{~S}$, which we also found for the corresponding batch copolymer. The explanation might be the same in this case, there could be a tail stretching towards lower fractions of $\mathrm{S}$. This then indicates that there is still considerable composition drift occurring, and this is not surprising if we com-

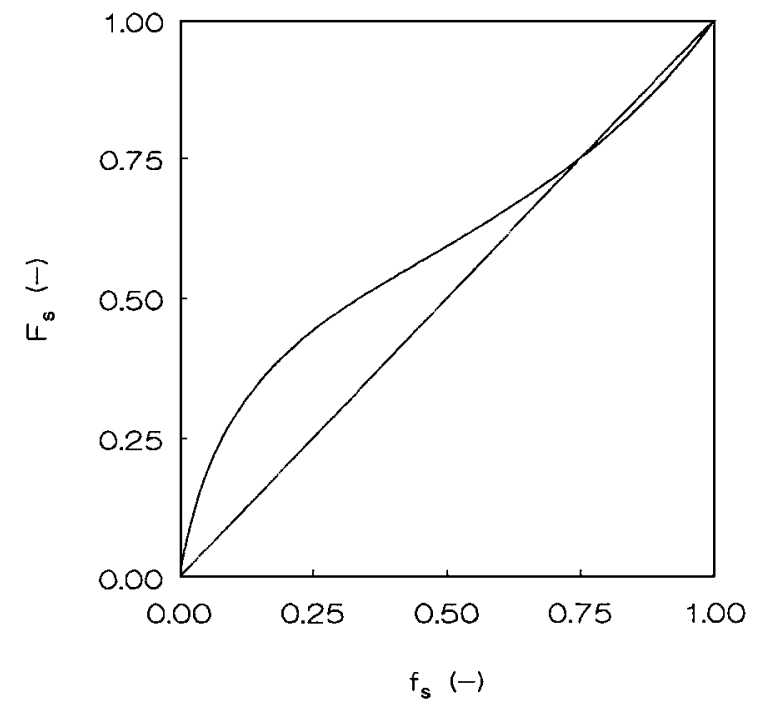

Figure 2 Depiction of the instantaneous copolymer composition $\left(F_{\mathrm{S}}\right)$ as a function of composition of the feed $\left(f_{\mathrm{S}}\right)$ for an S-MA free radical copolymerization at $50^{\circ} \mathrm{C}$ with $r_{\mathrm{S}}=0.73$ and $r_{\mathrm{MA}}=0.19$ (ultimate model). 

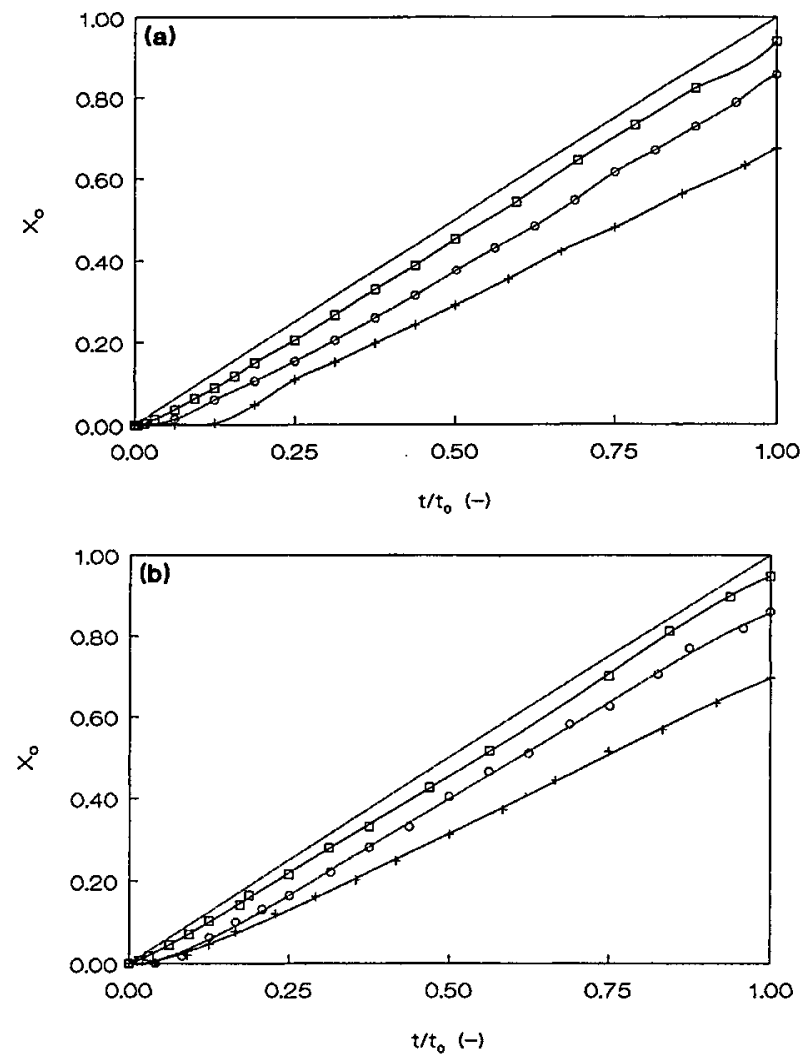

Figure 3 Overall conversion versus fractional time ( $t_{0}$ $=$ addition time) of the experiments under starved conditions with different addition times: (+) $4 \mathrm{~h}$; (O) $8 \mathrm{~h}$; (口) $32 \mathrm{~h}$; (a) $F_{\mathrm{S}}=0.50$; (b) $F_{\mathrm{S}}=0.80$.

pare the addition time of the monomers $(4 \mathrm{~h})$ to the total reaction time of the batch product, which is about 4-5 h. Most probably this reaction is not starved at all, but rather flooded. The average composition here was also $50 \%$ as determined with ${ }^{1} \mathrm{H}$ NMR. Both figures indicate that the lower the addition rate, the more homogeneous the products are. This effect is in accordance with the fact that lower addition rates lead to higher instantaneous conversions, i.e., less composition drift. It is a direct consequence of the fact that the reacting system has more time to reach the steady state with low addition rates. If we compare our results with those of van Doremaele et al., ${ }^{14}$ we see that the effect of addition rate on homogeneity in the case of $25 \mathrm{~mol} \% \mathrm{~S}$ is smaller than in the case of $50 \mathrm{~mol} \%$. This was not expected, because the above-mentioned batch reactions show that composition drift is larger in the case of low fractions of S. However, the effect may be explained by the fact that $\bar{k}_{p}$, the average propagation rate coefficient, is dependent on the composition of the monomer mixture. ${ }^{23}$ Since the prop- agation rate coefficient, $k_{p}$, of MA is much higher than that of $\mathrm{S}$, the system with the lower fraction of $S$ may reach the steady state at an earlier stage. Another possibility might be a difference in rate of nucleation, as the polymerization rate is strongly dependent on the number of particles. The production rate of oligomers in the aqueous phase is probably much larger in the case of MA-rich compositions, because of the relatively large concentration in the aqueous phase and the high $k_{p}$ of MA. The average number of radicals per particle $(\bar{n})$ could also be quite different in each case. Furthermore, we have to notice that, in the case of $80 \mathrm{~mol} \% \mathrm{~S}$, the effect of addition rate on homogeneity is smaller than in both other cases, since this composition is near the azeotropic composition. Composition drift in this case is negligible and the effect of $\bar{k}_{p}$ on the onset of steady state is not noticeable in the CCDs. Furthermore, the difference between $\bar{k}_{p}$ at $80 \mathrm{~mol} \%$ and at $50 \mathrm{~mol} \%$ system is not very large.
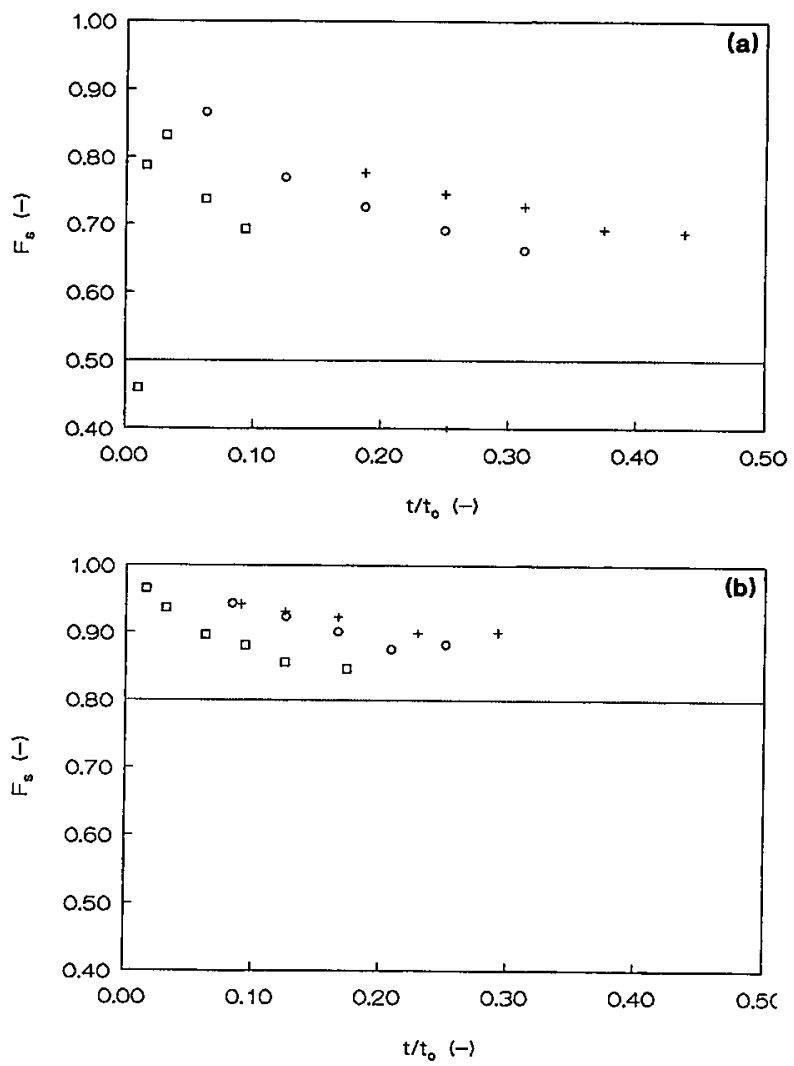

Figure 4 Copolymer composition (measured with ${ }^{1} \mathrm{H}$ NMR) versus fractional time ( $t_{0}=$ addition time) of the reactions under starved conditions with different addition times: (+) $4 \mathrm{~h}$; (O) $8 \mathrm{~h}$; ( $\square$ ) $32 \mathrm{~h}$; (a) $F_{\mathrm{S}}=0.50$; (b) $F_{\mathrm{S}}$ $=0.80$. (The solid line represents the overall fraction of S.) 

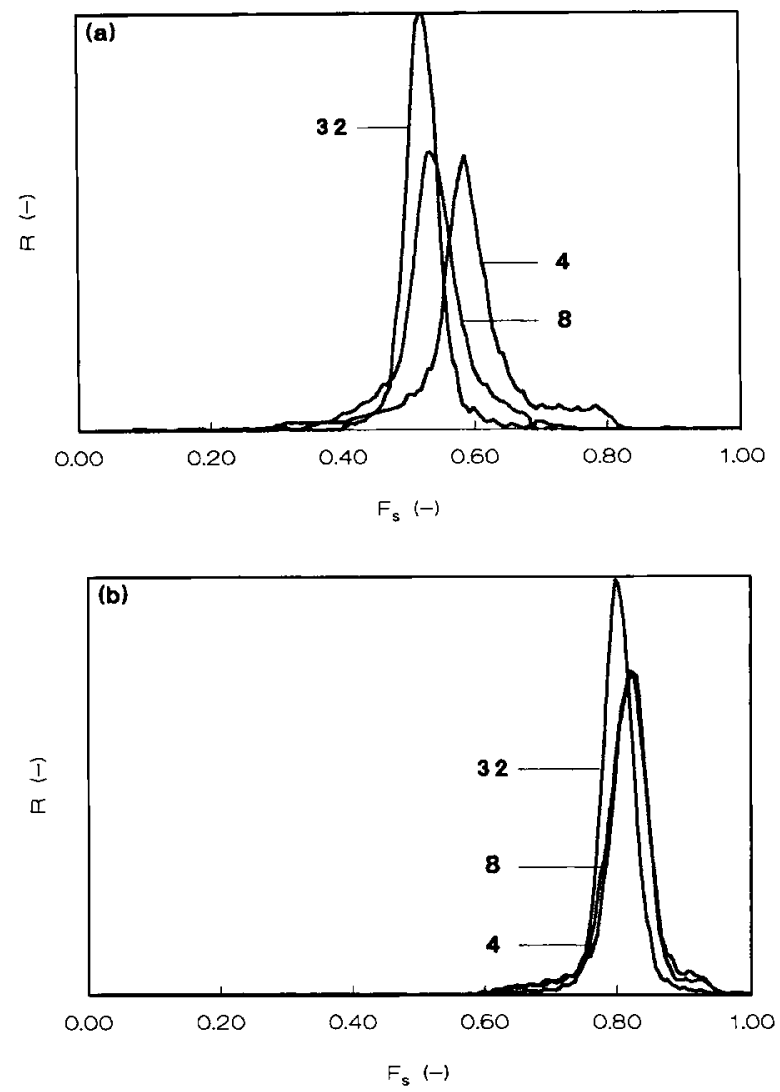

Figure 5 Experimentally determined CCDs of reactions under starved conditions. Addition times $(h)$ are indicated in the figure. (a) $F_{\mathrm{S}}=0.50$; (b) $F_{\mathrm{S}}=0.80 . R$ designates relative abundance (arbitrary units).

\section{Optimal Addition Rate Profiles}

As stated in the Introduction, Arzamendi and Asua ${ }^{11,12}$ were the first to report on the possibility to produce homogeneous emulsion copolymers via a method that is referred to as addition with an optimal addition rate profile. This way the ratio of the monomer concentrations inside the polymer particles can be fixed at a value that ensures the formation of a homogeneous copolymer of the desired composition. Furthermore, the concentrations of the monomers in the particles are much higher than they are in monomer starved reactions. This leads to higher polymerization rates and therefore to shorter reaction times.

In order to comply with the above conditions (constant ratio and high concentrations), the following strategy was applied by Arzamendi and Asua, and in our group by van Doremaele et al. ${ }^{1,14}$; we shall discuss both methods and adopt the strong points of both. The reactor is precharged with a seed to ensure relatively constant numbers of particles. All ingredients are added as well as all of the less reactive monomer [VAc in the case of MA-VAc copolymerizations (Arzamendi and Asua ${ }^{11,12}$ ), MA in the case of S-MA copolymerizations (van Doremaele et al. ${ }^{1,14}$ ) ] and part of the more reactive monomer. The amount of precharged more-reactive monomer is crucial. It is calculated so that the amount ensures formation of copolymer of the desired composition as soon as the reaction is started. This calculation is based on mass balances, monomer partitioning data, and reactivity ratios.

The remaining part of the more reactive monomer is then added during the reaction at a rate that is variable in time, depending on the reaction rate and the change in volume of the various phases (monomer partitioning). The difficulty of this strategy lies in the determination of the optimal addition rate profile. Arzamendi and Asua and van Doremaele et al. looked at the problem from different angles, but arrived at methods that are intrinsically the same. Arzamendi and Asua ${ }^{11}$ first developed a mathematical model for calculating the optimal addition rate profile for a seeded reaction where they precharged all of the VAc and part of the MA. The calculation of $\bar{n}$ was based on the equation derived by Ugelstad and Hansen. ${ }^{24}$ However, in a second paper, ${ }^{12}$ the same authors stated that several parameters needed for the calculation of $\vec{n}$ are not known and that it is therefore not possible to calculate the optimal addition rate profile without further experiments. To overcome this problem, they developed a semiempirical method to calculate the time evolution of $\bar{n}$. Using thermodynamic equilibrium equations according to Ugelstad et al. ${ }^{25}$ and the reactivity ratios, they calculated the amount of MA needed in the initial charge. Then they carried out an experiment where they added the remaining part of MA at a constant rate and calculated $\bar{n}$ with help of a model and the experimental results of this first reaction. Then $\vec{n}$ was correlated with the volume fraction of polymer in the particles. This correlation was used to calculate the optimal addition rate profile. If the results of the reaction that was carried out with the new addition rate profile indicated that the copolymer composition deviated from the desired value, then the procedure was repeated. The authors pointed out that the dependence of $\bar{n}$ on the volume fraction of polymer was the critical one. This was refuted by us, ${ }^{14}$ and we stated that $\bar{n}$ is also dependent on a number of other variables, especially when $\bar{n}$ is lower than 0.5. Arzamendi et al. ${ }^{15}$ also studied a system where $\bar{n}$ was lower than 0.5 , and they correlated $\bar{n}$ to the volume fraction of polymer and particle diameter. We used another approach, i.e., we 
compared the experimentally found addition profile with the calculated optimal addition profile in each iteration step. (Note that an addition rate profile is not the same as an addition profile. This will be explained below.) This means that it is not necessary to calculate $\bar{n}$ in each iteration step. The procedure is recalled briefly hereafter, but a more detailed description was given earlier. ${ }^{14}$

(i) We calculated the amount of $\mathrm{S}$ that is needed to produce the right copolymer at the beginning of the reaction (as did Arzamendi and Asua ${ }^{12}$ ), and we determined a correlation between amount of $S$ to be added $\left(A_{\mathrm{S}}^{*}\right)$ and instantaneous molar conversion $\left(x_{\text {inst }}\right): A_{\mathrm{S}}^{*}=g\left(x_{\text {inst }}\right)$, the calculated optimal addition profile (where $*$ indicates profile is optimal). This correlation is unique and dependent only on reactivity ratios and monomer partitioning. Only if the reaction is carried out in such a way that the experimental dependency of added amount of $S$ on instantaneous molar conversion corresponds exactly to the calculated dependency $A_{\mathrm{S}}^{*}$ $=g\left(x_{\text {inst }}\right)$, the fraction of $S$ in the particles will be constant and have the desired value, and the copolymer will be homogeneous. To meet this condition, one needs to find an optimal addition rate profile $\left[A_{\mathrm{S}}^{*}=h(t)\right]$.

(ii) The next step is to carry out a reaction and determine the conversion-time curve, $x_{\text {inst }}$ $=f(t)$.

(iii) The experimental conversion-time curve is combined with $A_{\mathrm{S}}^{*}=g\left(x_{\text {inst }}\right)$ to give a better addition rate profile $\mathrm{A}_{s}=h(t)$.

This new addition rate profile is then used in step (ii) until the profile is not significantly different from the previous one.

In the present study, we applied this procedure with the exception that in the present case $x_{\text {inst }}$ was not the instantaneous molar conversion but the instantaneous weight conversion, which means that it is not necessary to follow the partial molar conversions of the monomers with gas chromatography. Furthermore, the initial runs that were carried out in each iteration, were not based on the assumption that $\bar{n}=0.5$, as did van Doremaele et al., ${ }^{14}$ but were done with a constant addition rate of $\mathrm{S}$, as did Asua et al. ${ }^{12}$

We determined the optimal addition rate profile for homogeneous copolymers with 25,50 , and 80 mol \% S. As stated in the Introduction, the addition rate profile for $25 \mathrm{~mol} \% \mathrm{~S}$ was determined previously, ${ }^{14}$ but in this case we used a different seed latex (different particle diameter). Therefore, the polymerization rate is different and also the addition rate profile. We used sodium persulfate as initiator in stead of potassium persulfate, but we applied the same molar concentration.

In Figure 6, we plotted the results of the calculations with help of a model simulation ( SIEMCO $^{1}$ ) to obtain the correlation $A_{\mathrm{S}}^{*}=g\left(x_{\text {inst }}\right)$ for each composition. Then we performed the iteration procedure as described above. In the initial runs for 50 and 80 mol $\% \mathrm{~S}$ we added the $\mathrm{S}$ at a constant rate based on the reaction rate of the corresponding batch reactions. The addition rate profile of the initial run for $25 \mathrm{~mol} \%$ was based on the addition rate profile that was obtained before. ${ }^{14}$ In all cases we obtained an optimal addition rate profile after three or four iteration steps, comparable to what was found earlier for $25 \mathrm{~mol} \% \mathrm{~S}$. Figure 7 shows the experimental results of the iteration procedures, i.e., $A_{\mathrm{S}}$ versus instantaneous conversion for the three compositions. For comparison we also depicted the calculated optimal addition profiles. As can be seen from both Figures 6 and 7, the difficulty with the profile for 80 $\mathrm{mol} \% \mathrm{~S}$ was to find the time at which the reaction reached the conversion at which the addition had to be started.

The best impression of such an iteration procedure is obtained by looking at the CCDs of all these reactions as depicted in Figures $8 \mathrm{a}, 8 \mathrm{~b}$, and $8 \mathrm{c}$ corresponding to the reactions with 25,50 , and $80 \mathrm{~mol}$ $\% \mathrm{~S}$. One can clearly see that the homogeneity of the copolymers produced improves with every iter-

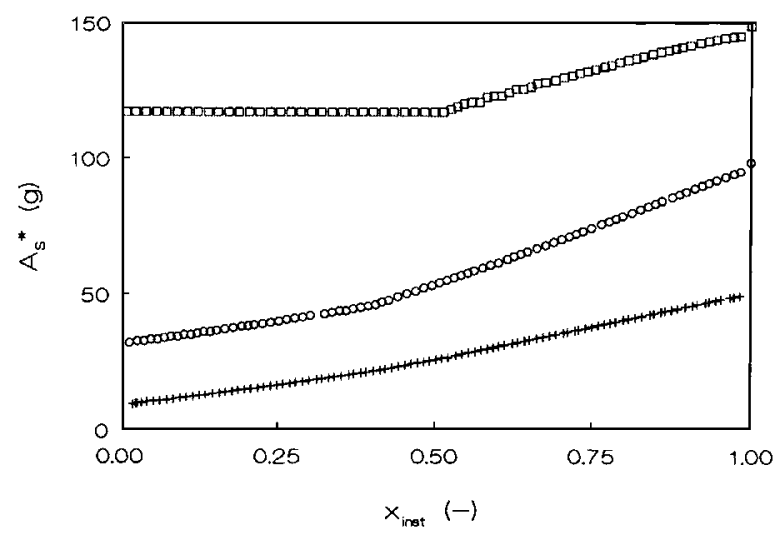

Figure 6 Optimal addition profiles (calculated with model simulations) plotted as amount of $\mathbf{S}$ to be added ( $A_{\mathrm{S}}^{*}$ ) as function of instantaneous conversion $\left(x_{\text {inst }}\right)$ for three different compositions: $(+) F_{\mathrm{S}}=0.25$; (O) $F_{\mathrm{S}}=0.50$; (ㅁ) $F_{\mathrm{S}}=0.80$. 

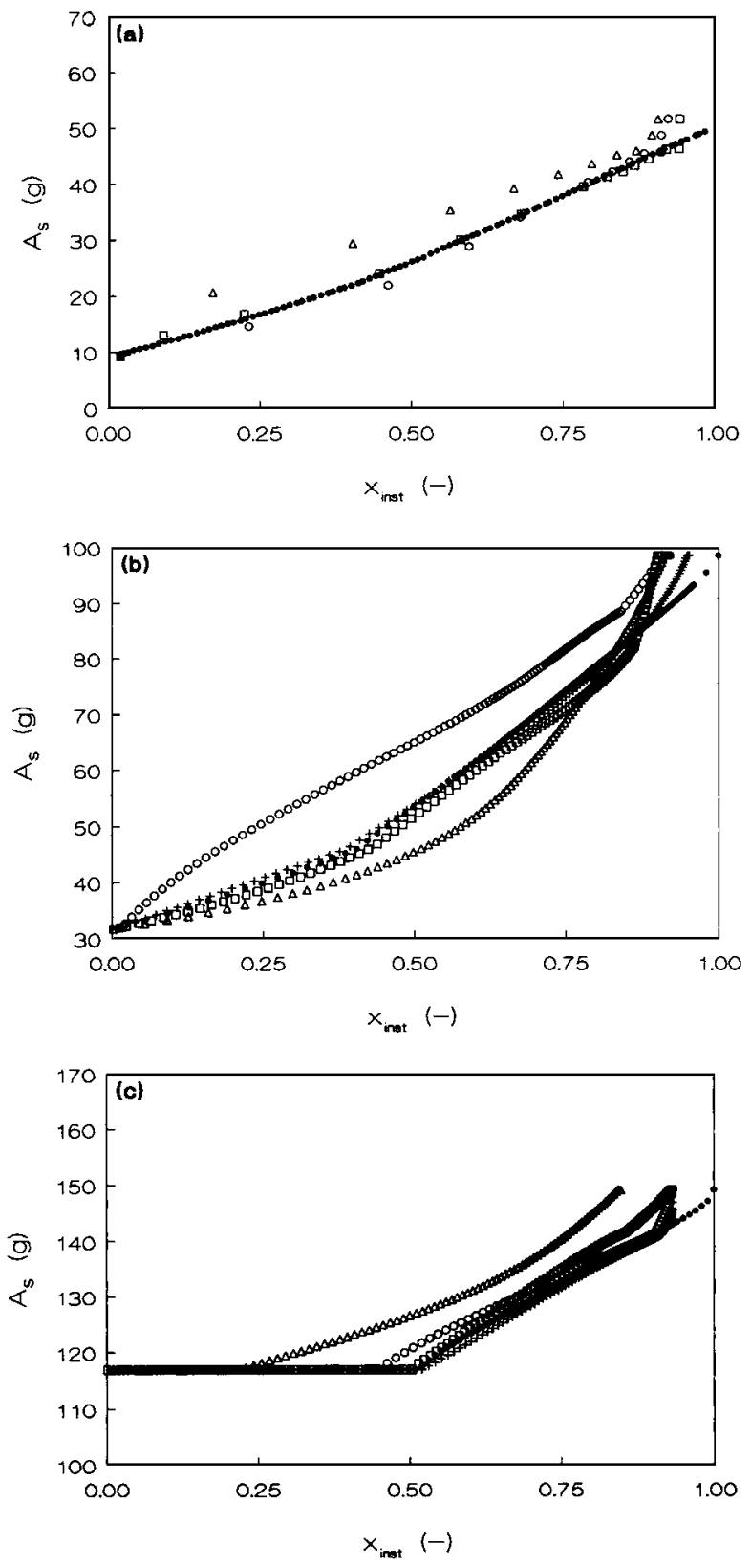

Figure 7 Representation of the successive experimental reactions in the iteration procedure to find the optimal addition profiles. Amount of $\mathrm{S}$ to be added $\left(A_{\mathrm{S}}\right)$ as function of instantaneous conversion $\left(x_{\text {inst }}\right) .(\Delta) 1$ st run; $(O)$ 2nd run; ( $\square$ ) 3rd run; ( +) 4th run; calculated optimal addition profile (-) (see also Fig. 6) . (a) $F_{\mathrm{S}}=0.25$; (b) $F_{\mathrm{S}}=0.50$; (c) $F_{\mathrm{S}}=0.80$.

ation step, as expected. Furthermore, one can see that the heterogeneity of the copolymers of the first steps is in all cases already quite limited, and this must be the result of good initial guesses. If we would have determined the CCD after each run (and not after the whole procedure was already finished), the number of runs could have been smaller. So it seems that judging the optimality is best done by looking at the CCDs rather than at the addition profiles. The reactions performed to obtain copolymers with $80 \mathrm{~mol} \% \mathrm{~S}$, as mentioned before, being carried out under almost azeotropic conditions, all resulted in homogeneous copolymers, notwithstanding the fact that the addition profiles differed considerably.
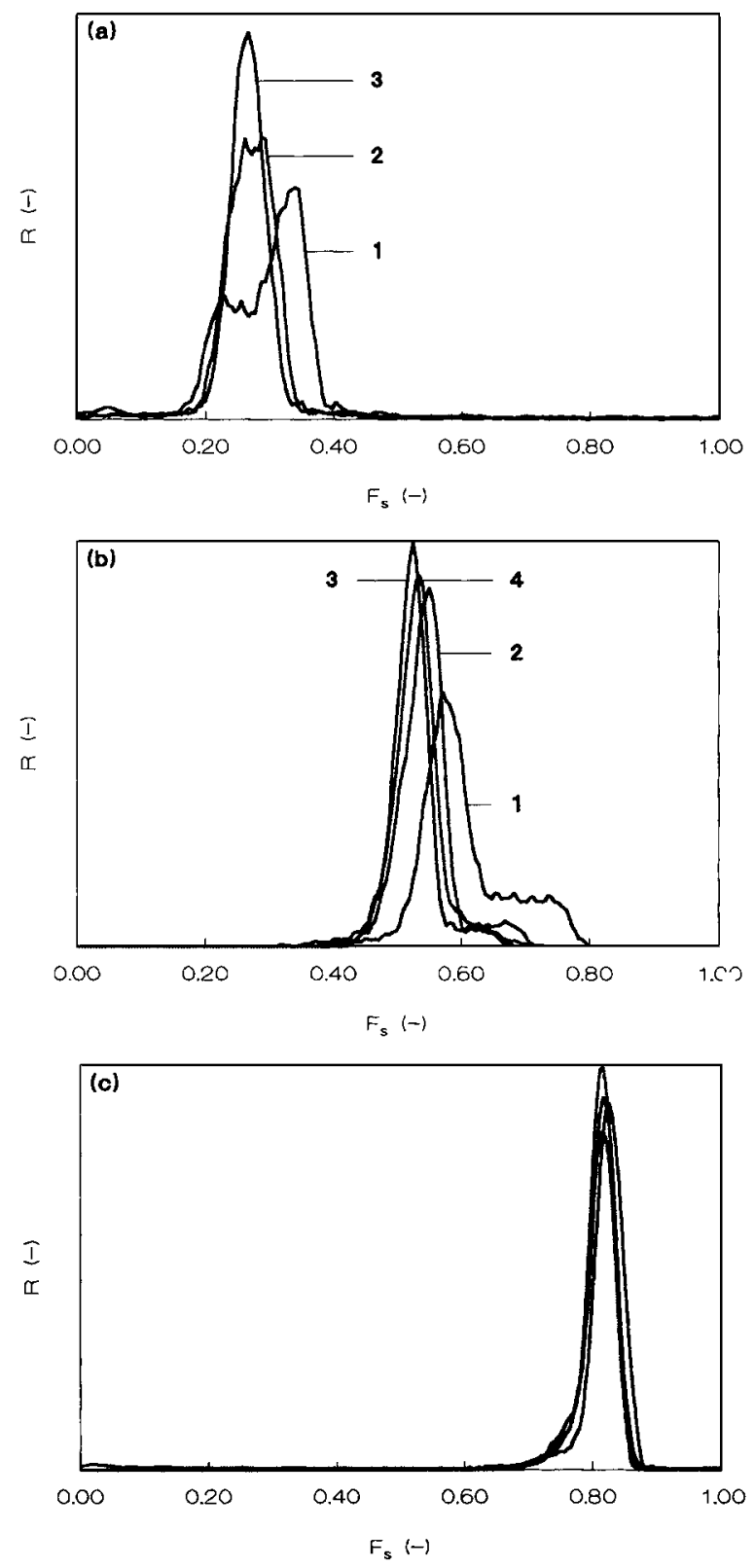

Figure 8 Experimentally determined CCDs of successive reactions in the iteration procedure to find the optimal addition rate profiles. Run numbers are indicated in the figures, except in Figure $8(\mathrm{c})$. (a) $F_{\mathrm{S}}=0.25$; (b) $F_{\mathrm{S}}$ $=0.50 ;$ (c) $F_{\mathrm{S}}=0.80 . R$ designates relative abundance (arbitrary units). 
In Figure 9 we depicted the dependency of $\bar{n}$ on conversion for the reactions with optimal addition rate profiles. The calculations were based on the penultimate model. ${ }^{23}$ Clearly this dependency is influenced by the ratio S/MA. However, if the ratio $\mathrm{S} / \mathrm{MA}$ is different in the particles, it is also different in the water phase. So by changing the overall ratio, the ratios in both particle and aqueous phase change, and therefore it is not possible to draw any mechanistic conclusions. Furthermore, the particle number is not the same in each reaction. Only a more detailed kinetic study could perhaps reveal some kinetic parameters.

\section{Addition Rate Profile for Heterogeneous Copolymers}

Heretofore all efforts were aimed at producing homogeneous copolymers. However, it might equally well be that one wishes to make copolymers that have a broad composition distribution rather than a narrow distribution. Whatever the shape of the CCD one wants to obtain, the reaction will have to be controlled in a similar way as shown, necessary to produce homogeneous copolymers. In order to illustrate this hypothesis, we attempted to make a copolymer with a CCD of predefined broadness profile.

In order to be able to compare the properties of such an emulsion copolymer with a copolymer with the same average composition but with a narrow distribution, we tried to make a copolymer consisting of $25 \mathrm{~mol} \mathrm{\%} \mathrm{S}$ on the average, but with a composition distribution ranging from 0 to $50 \mathrm{~mol} \% \mathrm{~S}$. In Figure 10 we depicted schematically the CCD of such a copolymer.

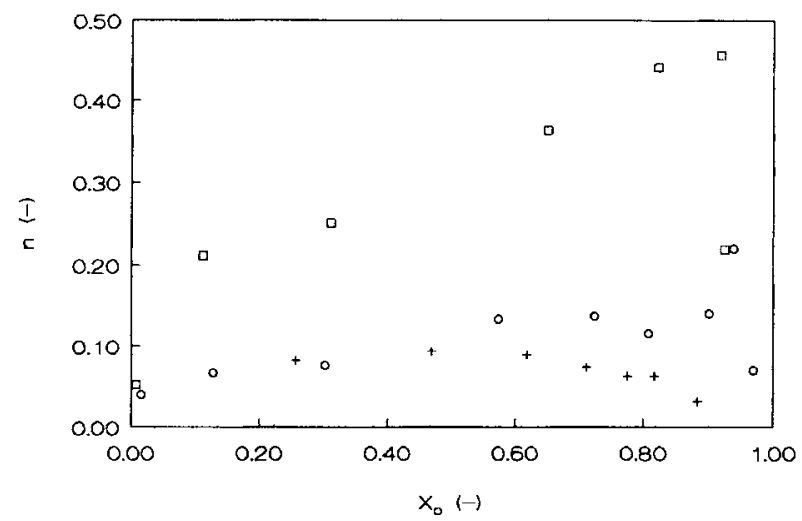

Figure 9 Average number of radicals per particle $(\bar{n})$ as a function of overall conversion for the reactions with the optimal addition rate profiles: $(+) F_{\mathrm{S}}=0.25$; (O) $F_{\mathrm{S}}$ $=0.50 ;(\square) F_{\mathrm{S}}=0.80$.

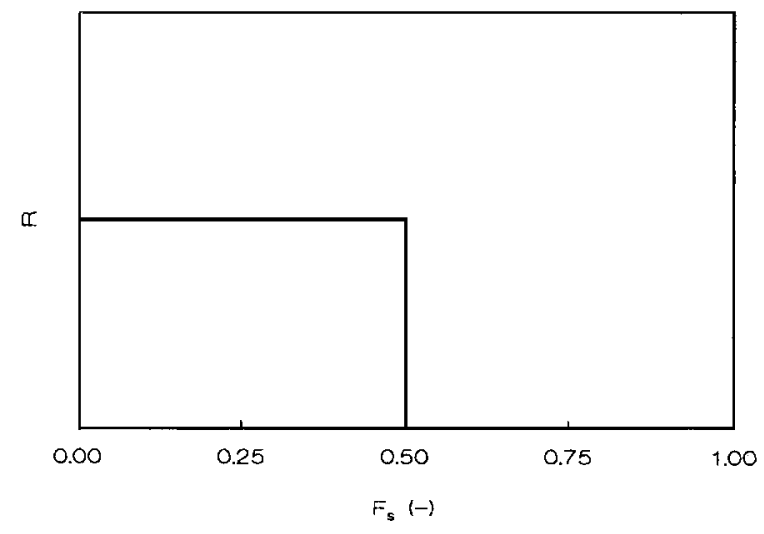

Figure 10 Schematic CCD of a copolymer of hypothetical heterogeneity.

To accomplish this, we applied the following strategy, comparable to that applied for the preparation of the homogeneous copolymers. In the beginning of the reaction, poly (methyl acrylate) (PMA) is formed, and slowly the instantaneous composition of the copolymer is shifted towards higher fractions of $S$, in fact, a composition drift that is reversed compared to the drift occurring in batch emulsion copolymerizations. The highest instantaneous fraction of $\mathrm{S}$ incorporated has to be 50 $\mathrm{mol} \%$. If one would try to make the same copolymer in reversed order, i.e., starting at $50 \mathrm{~mol} \% \mathrm{~S}$ and ending at $0 \mathrm{~mol} \% \mathrm{~S}$, one would have to add too much MA in the beginning, leaving no MA to add to control the reaction. This is a direct consequence of the copolymerization behaviour of $S$ and MA. With help of mass balances, thermodynamic cor-

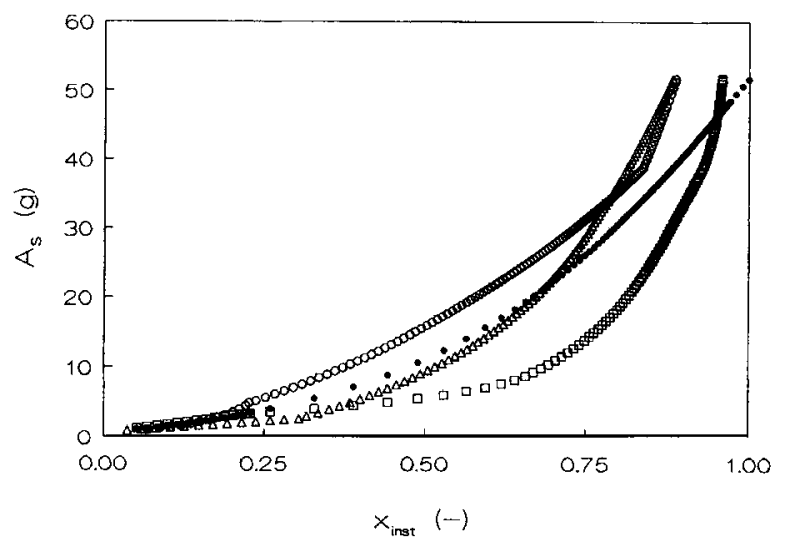

Figure 11 Experimentally determined CCDs of successive copolymer products in the iteration procedure to find the addition rate profile for the heterogeneous copolymer defined in Figure 10. Run numbers are indicated in the figure. $R$ designates relative abundance (arbitrary units). 
relations, and reactivity ratios, we calculated the dependency $A_{\mathrm{S}}^{*}=g\left(x_{\text {inst }}\right)$. The further procedure is the same as with the optimal addition rate profiles.

The first run was based on a reaction where the total amount of MA was added to the reactor, and $\mathrm{S}$ was added at a constant rate. Figure 11 shows the $\mathrm{CCD}$ of this reaction (run no. 1). One can see that the distribution already resembles vaguely the one we are looking for. However, the difficulty in the present case seems to be the presence of all the MA at the beginning of the reaction. Since MA is a very fast reacting monomer, it is very hard to find the optimal addition rate profile for the first part of the reaction. The CCDs of the first reactions manifest this by showing a relatively large PMA peak. To improve the CCD, we carried the iteration procedure (runs 2 and 3 in Fig. 11). But these runs did not seem to get much closer to the desired CCD. In Figure 12 we depicted the amount of $S$ to be added versus instantaneous conversion for the three successive reactions. The figure illustrates that the first profile is already comparable to the calculated addition rate profile and that the first part of the profiles improve with increasing run number. This may indicate that the iteration procedure is only very slow. Considering this, we decided not to continue it. We think that if one were to make a heterogeneous copolymer with an average composition of $50 \% \mathrm{~S}$, with $F_{\mathrm{S}}$ ranging from 0.25 to 0.75 , the procedure would be easier to carry out.

\section{Molecular Weights}

As stated earlier in this work we added NDM to minimize the effect of addition strategy on the

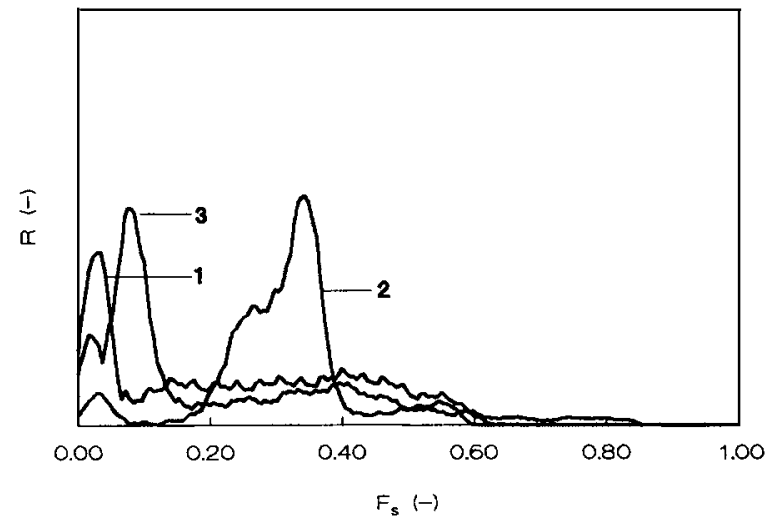

Figure 12 Representation of the successive experimental reactions in the iteration procedure to find the addition rate profile for the heterogeneous copolymer defined in Figure 10. Amount of $\mathrm{S}$ to be added $\left(A_{\mathrm{S}}\right)$ as function of instantaneous conversion $\left(x_{\text {inst }}\right) .(\triangle)$ 1st run; $(O)$ 2nd run; ( $\square$ ) 3rd run; ( $)$ calculated addition rate profile.
Table IV Molecular Weights of Some of the S-MA Copolymers Measured with GPC ${ }^{a}$

\begin{tabular}{lccc}
\hline & \multicolumn{3}{c}{$M_{n}$} \\
& $F_{S}$ & $(\mathrm{~kg} / \mathrm{mol})$ & $M_{w} / M_{n}$ \\
\hline Batch & 0.25 & 48.6 & 2.3 \\
Batch, no NDM & & 476 & 7.5 \\
Starved conditions (8 h) & 0.25 & 56.6 & 2.5 \\
Optimal addition & 0.25 & 29.0 & 2.1 \\
Batch & 0.50 & 67.7 & 2.5 \\
Starved conditions (8 h) & 0.50 & 54.6 & 2.4 \\
Optimal addition & 0.50 & 33.1 & 2.1 \\
Batch & 0.80 & 34.6 & 2.8 \\
Starved conditions (8 h) & 0.80 & 44.9 & 3.3 \\
Optimal addition & 0.80 & 60.7 & 3.3 \\
\hline
\end{tabular}

${ }^{a}$ In all cases NDM was added unless indicated otherwise. $M_{n}$ is the number average molecular weight, $M_{w}$ the weight average molecular weight, and the polydispersity is the ratio of these.

${ }^{b}$ The recipe for this reaction is the same as for the batch reaction with NDM.

MMD. We measured the MMDs of all products mentioned in this work with gel permeation chromatography (GPC). In Table IV, the molecular weights are given of several copolymers. It can be clearly seen that the molecular weights are relatively small, compared to a batch reaction carried out without NDM, but, more importantly, there is no obvious effect of addition strategy on MMD. The number average molecular weights $\left(M_{n}\right)$ vary somewhat, but show no clear trend. One could perhaps suggest a trend in the polydispersity $\left(M_{w} / M_{n}\right)$, which seems to increase going from $F_{\mathrm{S}}=0.25$ to $F_{\mathrm{S}}$ $=0.80$. The polydispersity is in all cases much lower than what is obtained without NDM, which indicates that adding NDM is a good way to avoid large differences in MMD.

The copolymers mentioned in this work will be used in a study of the effect of the shape of the CCD on the mechanical properties.

\section{CONCLUSIONS}

Batch emulsion copolymerization of styrene and methyl acrylate leads to copolymers with broad chemical composition distributions or even bimodal distributions. Homogeneous emulsion copolymers of styrene and methyl acrylate with various fractions of styrene can be produced via two different strategies. Using constant addition rates under starved conditions leads to homogeneous copolymers if long addition times are used. Applying optimal addition rate profiles (adding all the methyl acrylate to the reactor at the beginning and adding the styrene at a rate that varies in time) results in homogeneous 
copolymers but with reaction times comparable to the times needed for the batch reactions. The information about composition drift in batch reactions is seen to be useful in explaining how quickly an optimal addition rate profile can be found. It is shown that HPLC is of great value in determining whether an optimal addition rate profile is really optimal. The reactions with optimal addition rate profiles did not give enough information to draw conclusions about the influence of the ratio styrene/ methyl acrylate on $\bar{n}$. The strategy used to produce homogeneous copolymers with optimal addition rate profiles can be applied to the production of copolymers with a predefined broad CCD. However, in our case the iteration procedure seemed to be very slow. If NDM is used, the molecular weights are quite low in all instances, and there is no obvious effect of addition strategy, though the polydispersity seems to increase with increasing mole fraction $S$.

Eventually the homogeneous and heterogeneous copolymers with varying fractions of styrene will be used to demonstrate the effect of the shape of the CCDs and average chemical composition on the mechanical properties of these kinds of emulsion copolymers.

The authors would like to thank Wieb Kingma for providing the MMDs.

\section{REFERENCES}

1. G. H. J. van Doremaele, Ph.D. thesis (1990), Eindhoven University of Technology, Eindhoven, The Netherlands.

2. K. Chujo, Y. Harada, S. Tokuhara, and K. Tanaka, J. Polym. Sci. C, 27, 321 (1969).

3. J. Šnupárek, Angew. Makromol. Chem., 25, 113 (1972).

4. R. A. Wessling and D. S. Gibbs, J. Macromol. Sci. Chem., A-7, 647 (1973).

5. J. Šnupárek and F. Krška, J. Appl. Polym. Sci., 20, 1753 (1976).

6. J. Šnupárek and F. Krška, J. Appl. Polym. Sci., 21, 2253 (1977).

7. J. Šnupárek and K. Kašpar, J. Appl. Polym. Sci., 26, 4081 (1981).
8. M. S. El-Aasser, T. Makgawinata, J. W. Vanderhoff, and C. Pichot, J. Polym. Sci. Polym. Chem. Ed., 21, 2363 (1983).

9. S. C. Misra, C. Pichot, M. S. El-Aasser, and J. W. Vanderhoff, J. Polym. Sci. Polym. Chem. Ed., 21, 2383 (1983).

10. T. Makgawinata, M. S. El-Aasser, A. Klein, and J. W. Vanderhoff, J. Dispersion Sci. Technol., 5, 301 (1984).

11. G. Arzamendi and J. M. Asua, J. Appl. Polym. Sci., 38, 2019 (1989).

12. G. Arzamendi and J. M. Asua, Makromol. Chem. Macromol. Symp., 35/36, 249 (1990).

13. G. Arzamendi and J. M. Asua, Ind. Eng. Chem. Res., 30, 1342 (1991).

14. G. H. J. van Doremaele, H. A. S. Schoonbrood, J. Kurja, and A. L. German, J. Appl. Polym. Sci., 45, 957 (1992).

15. G. Arzamendi, J. R. Leiza, and J. M. Asua, J. Polym. Sci. Polym. Chem. Ed., 29, 1549 (1991).

16. B. Urquiola, G. Arzamendi, J. R. Leiza, Z. Aranzazu, J. M. Asua, J. Delgado, M. S. El-Aasser, and J. W. Vanderhoff, J. Polym. Sci. Polym. Chem. Ed., 29, 169 (1991).

17. G. Arzamendi, J. C. de la Cal, and J. M. Asua, Angew. Makromol. Chem., 194, 47 (1992).

18. T. O. Broadhead, A. E. Hamielec, and J. F. MacGregor, Makromol. Chem. Suppl., 10/11, 105 (1985).

19. A. E. Hamielec, J. F. MacGregor, and A. Penlidis, Makromol. Chem. Macromol. Symp., 10/11, 571 (1987).

20. R. W. Sparidans, H. A. Claessens, G. H. J. Van Doremaele, and A. M. van Herk, J. Chromatogr., 508, 319 (1990).

21. G. H. J. Van Doremaele, J. Kurja, H. A. Claessens, and A. L. German, Chromatographia, 31, 493 (1991).

22. B. Li and B. W. Brooks, Polym. Int., 29, 41 (1992).

23. T. P. Davis, K. F. O'Driscoll, M. C. Piton, and M. A. Winnik, Polym. Int., 24, 65 (1991).

24. J. Ugelstad and F. K. Hansen, Rubber Chem. Technol., 49, 536 (1976).

25. J. Ugelstad, P. C. Mork, H. R. Mfutukamba, E. Soleimany, J. Nordhuus, K. Nustad, R. Schmid, A. Berge, T. Ellingsen, and $\mathrm{O}$. Aune, in Science and Technology of Polymer Colloids, (G. W. Poehlein, R. H. Ottewil, and J. W. Goodwin, Eds.), NATO ASI Ser., 1983, Vol. 1, p. 51 .

Received September 14, 1992

Accepted January 13, 1993 